\title{
Cushing's Disease From An Ectopic Parasellar Adenoma
}

\author{
Philip C Johnston ${ }^{1}$, Laurence Kennedy ${ }^{1}$, Amir H Hamrahian ${ }^{1}$ Robert J Weil ${ }^{2}$
}

Department of Endocrinology and Diabetes ${ }^{1}$, Department of Neurosurgery ${ }^{2}$,Cleveland Clinic, Ohio, USA

\section{BACKGROUND}

Cushing's disease is a result of adrenocorticotropic hormone (ACTH)-dependent hypercortisolism, whereby the majority of cases originate from the pituitary. In rare cases, the source of excess ACTH is from an ectopic pituitary adenoma, in which the clinical and biochemical picture can often be identical to intrasellar corticotroph adenomas.

Ectopic pituitary adenomas are defined as an adenoma that lies outside the sella and is completely distinct from the normal intrasellar pituitary gland, they can be associated with normal pituitary and in some cases, an empty sella.

\section{CASE}

A 34-year-old woman presented with a 12-month history of a labile mood, weight gain, easy bruising, irregular menses and hypertension.

The patient appeared cushingoid, biochemical investigations demonstrated hypercortisolism: $24 \mathrm{~h}$ urine-free cortisol $520.7 \mathrm{mcg}$ (4-50), ACTH $152 \mathrm{pg} / \mathrm{mL}$ (8-42); midnight salivary cortisol $510 \mathrm{ng} / \mathrm{dL} \quad(<100)$, 8 AM serum cortisol $28.5 \mathrm{mcg} / \mathrm{dL}(6.5-26)$ after a $1 \mathrm{mg}$ overnight dexamethasone suppression test (DST).

There was a $70 \%$ suppression of cortisol after an overnight high dose (8 $\mathrm{mg}$ ) DST, and a $50 \%$ increase in ACTH during a corticotropin releasing hormone (CRH) test consistent with pituitary mediated ACTH dependent Cushing's syndrome.

Gadolinium-enhanced MRI of the sella revealed an atypical enhancing mass $(0.70 .90 .5 \mathrm{~cm}$ ) lying above the pituitary gland (figure $1 \mathrm{~A}, \mathrm{~B}$; arrows).

The pituitary gland, within the sella, was normal. Given the presence of the atypical parasellar lesion which was felt to be the source of excess ACTH-secretion, trans-sphenoidal exploration without inferior petrosal sinus sampling (IPSS), was therefore undertaken.

\section{CASE}

At surgery, using an extended trans-sphenoidal approach to the pituitary to be able to reach the suprasellar intracranial space, extensive exploration of the sella, anterior and posterior pituitary, and parasellar region, as outlined by Oldfield was performed. A mucoid, non-encapsulated lesion located wholly in the suprasellar intracranial space, with its inferior aspect lying on but not transecting the diaphragm sella, was removed; it was dissected sharply free of the infundibulum. No tumour was identified within the sella or the pituitary gland.

After complete resection of the lesion pathology revealed a pituitary adenoma, with ACTH immunopositivity. At 6 months follow-up she remains in remission, with preservation of anterior pituitary function.

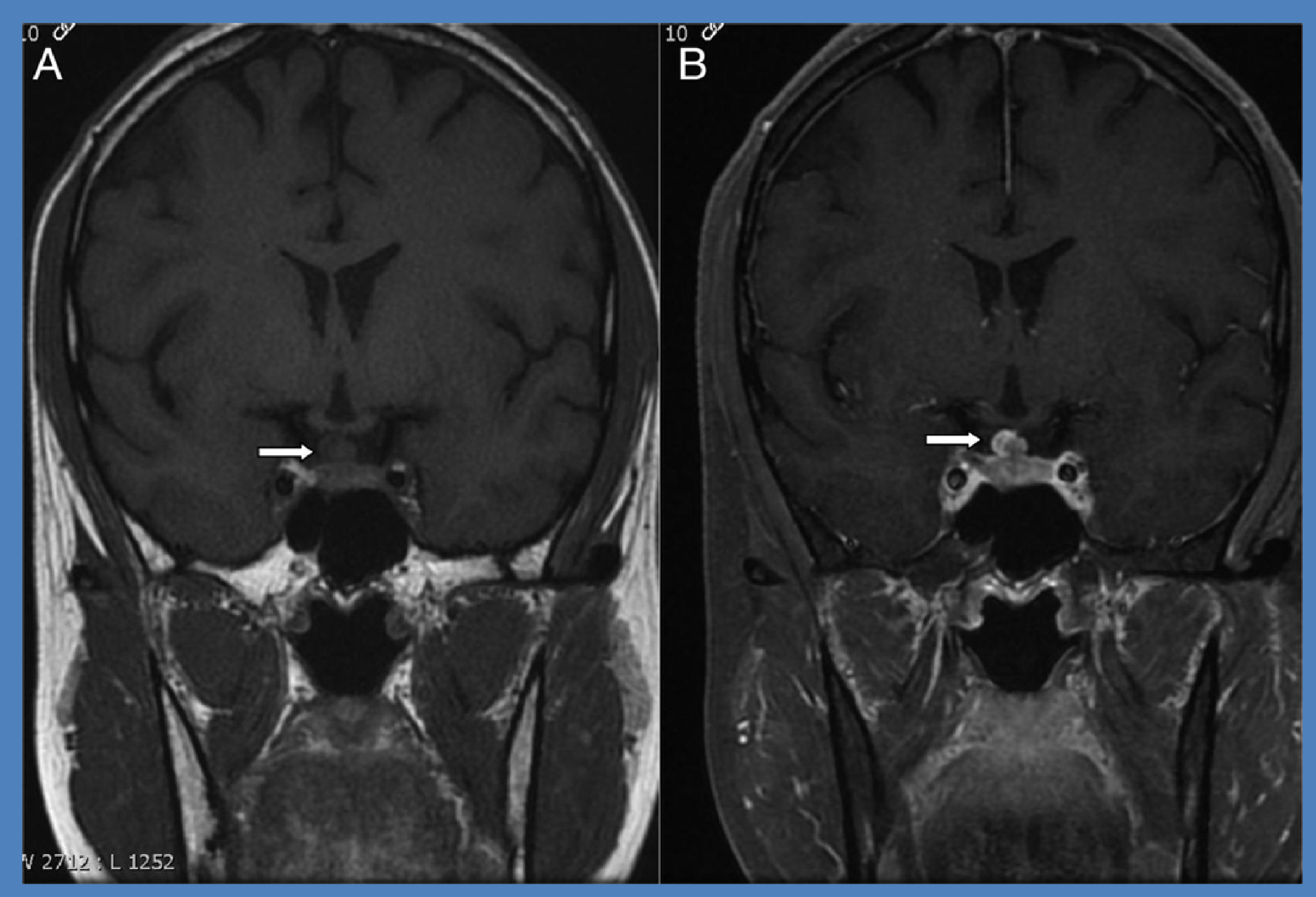

\section{DISCUSSION}

Various locations of ectopic pituitary adenomas have been reported, including the sphenoid sinus, nasopharynx, intracavernous sinus; and in this case, the suprasellar region.

Ectopic pituitary tumours have been proposed to arise mainly from pituitary rest cells from the embryonic remnants of Rathke's pouch, from aberrant migration of pituitary cells or from neoplastic transformation of the pharyngeal pituitary.

\section{CONCLUSION}

Ectopic ACTH-secreting adenomas can be difficult to diagnose, mainly because of their small size and unusual locations. In patients with Cushing's disease, careful pre-operative review of sellar imaging is imperative.

Ectopic pituitary adenomas are not always visible on imaging, and may explain why some patients with Cushing's disease have residual hypercortisolism after hypophysectomy . Johnston PC, et al PMJ 2014 